\title{
Number of Resorptions
}

National Cancer Institute

\section{Source}

National Cancer Institute. Number of Resorptions. NCI Thesaurus. Code C124637.

A measurement of the total number of resorptions in the uterus. 